\title{
Embedment tests perpendicular to the grain - optical measurements of deformation fields
}

\author{
J.C.M. (Dennis) Schoenmakers • S. Svensson
}

Received: 7 April 2009 / Published online: 9 January 2010

(C) The Author(s) 2009. This article is published with open access at Springerlink.com

\begin{abstract}
This paper reveals additional knowledge on the bearing behaviour of single fastener connections. By means of non-contact full-field deformation measurements the deformation fields were recorded for different test configurations. It is shown that embedment is a very local phenomenon causing large stress concentrations and gradients in the dowel vicinity. However, timber as being considered a highly orthotropic material loaded in the weak planes appears to be able to redistribute stresses and to activate material outside the dowel vicinity. This causes the ultimate strength to be governed by the deformation ability underneath the dowel. This effect is not detectable in case of rather small specimen geometries, however, it becomes evident in case of specimens of structural sizes. Finite element simulations show localization effects to be much more evident in case of isotropic materials like steel, what verifies an apparent load-sharing effect for timber perpendicular-to-grain.
\end{abstract}

\section{Bestimmung der Lochleibungsfestigkeit quer zur Faser - Optische Messungen der Verformungen}

Zusammenfassung In dieser Studie werden zusätzliche Erkenntnisse über das Tragverhalten einer Verbindung mit einem stiftförmigen Verbindungsmittel vorgestellt. Mittels berührungslosen Vollfeld-Verformungsmessungen wurde das Verformungsverhalten bei unterschiedlichen Versuchs-

J.C.M. (Dennis) Schoenmakers ( $₫$ )

Eindhoven University of Technology (TU/e), P.O. Box 513, 5600 MB Eindhoven, The Netherlands

e-mail: J.C.M.Schoenmakers@tue.nl

\section{S. Svensson}

Technical University of Denmark (DTU), Brovej, building 118, room 048, 2800 Lyngby, Denmark anordnungen erfasst. Es wurde gezeigt, dass die Lochleibungsfestigkeit ein stark lokales Phänomen ist, das hohe Spannungskonzentrationen und Gradienten im Bereich des Verbindungsmittels verursacht. Jedoch scheint es, dass Schnittholz, das als äußerst orthotropes Material gilt, bei Belastung quer zur Faser in der Lage ist, diese Spannungen umzulagern und vom Verbindungsmittel weiter entferntes Material zu aktivieren. Dadurch wird die Bruchfestigkeit durch die Verformbarkeit unterhalb des Verbindungsmittels bestimmt. Dieser Einfluss ist bei eher kleinen Prüfkörpern nicht erkennbar, wird jedoch bei Prüfkörpern in Gebrauchsabmessungen deutlich. Finite-Elemente-Simulationen zeigen, dass lokale Einflüsse im Fall von isotropen Materialien wie Stahl deutlicher ausgeprägt sind, was wiederum einen offenbaren Lastverteilungseffekt bei quer zur Faserrichtung beanspruchtem Schnittholz bestätigt.

\section{Introduction}

Timber in compression perpendicular to the grain shows hardening after an initial linear response. This behaviour is a result of restrained dilatation perpendicular to the grain associated with a multi-axial stress state in a highly orthotropic material. The load-carrying capacity appears, therefore, to be dependant of both the deformation of the compressed timber fibres and the ability of load sharing (material activation) within the material. According to Van der Put (2006) a strength increase as a result of increasing compressed timber volume can be noticed due to restrained dilatation. This is stated to be explained by the equilibrium method of plasticity using a slip-line field to represent the stress distribution in the specimen, as is shown for locally loaded blocks (sills). According to the theory the strength is proportional to the square root of the ratio between the loading area, st [mm], 
and the effective supporting area, $L t[\mathrm{~mm}]$, where $t$ is the constant width of the timber specimen, and $s$ and $L$ denote the lengths of the loading and supporting area, respectively (Fig. 1). The strength relation is shown in (1):

$f_{s}=f_{c ; 90} \sqrt{\frac{L t}{s t}}$

where $f_{s}$ is the bearing strength of the specimen and $f_{c ; 90}$ the standardized compressive strength perpendicular to the grain. In the context of the model, $f_{c ; 90}$ is used as a fitting parameter to calibrate the model with experiments.

Based on the results from experiments on timber sills of equal cross sectional dimensions and loading area but increasing lower bearing plate conducted by Suenson (see Kollmann 1955), the angle of stress distribution appears to be 1:1.5 since further increase of the supporting length does not result in a further increase of strength.

As presented by Van der Put and Leijten (2000) and Van der Put (1988), the equilibrium method of plasticity should be applied to estimate the embedding strength of dowel-type fasteners as well. In Van der Put and Leijten (2000), the method was employed to describe experiments reported by Ballerini (1999) where the angle of load sharing was assumed to be 1:1.5. Schoenmakers et al. (2009) have applied the model as well in order to compare experimental results of embedment tests performed on either full-constrained or non-constrained specimens (small-scale bending), see Fig. 2. There it is shown that the experimental results obtained by Whale and Smith (1986) and Sawata and Yasumura (2002) using both different test set-ups given in Fig. 2 are comparable. In addition, it is shown that it is

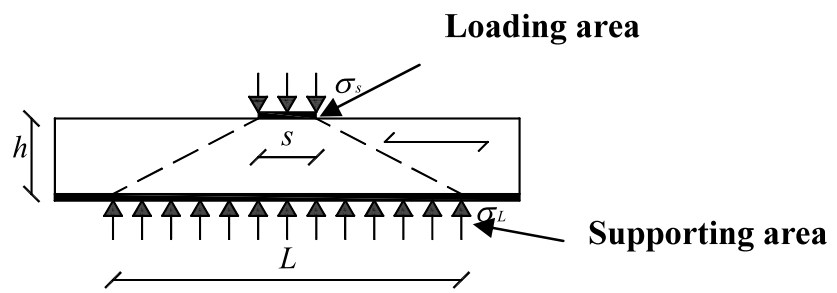

Fig. 1 Denomination and clarification of symbols used in (1) Abb. 1 Bezeichnung und Erläuterung der in (1) verwendeten Symbole possible to relate embedment strength values corresponding to certain deformation limits by simple linear interpolation of the non-linear branch of the load-slip response. Based on an angle of 1:1.5 and a loaded edge distance $h_{e}=4 d$ a reference strength was defined, for European redwood (Pinus sylvestris) (Whale and Smith 1986), loaded by a $6 \mathrm{~mm}$ diameter nail. From this the reference strength is found to be $f_{c ; 90 ; d=6 \mathrm{~mm}}=5.8 \mathrm{~N} / \mathrm{mm}^{2}$, according to (1). In order to relate different strength values associated with different fastener diameters the size effect is taken into account by means of Weibull weakest link theory.

This paper shows that in case of dowel-type fasteners the angle of stress distribution can indeed be taken as 1:1.5, in the situations analyzed. This angle appears not to be strongly affected by the applied set-up. Hence, similar equations can be used for timber blocks loaded perpendicular to the grain by either bearing plates or dowel-type fasteners.

\section{Materials and methods}

In order to investigate the load sharing angle three series of experiments were conducted: 9 full-constrained embedding tests $\left(\mathrm{A}_{\mathrm{i}-\mathrm{j}}\right)$ (Fig. 2a), 3 unconstrained embedding tests $\left(\mathrm{B}_{\mathrm{i}-\mathrm{j}}\right)$ (Fig. $2 \mathrm{~b}$ ), and 9 bending tests on full-scale beams $\left(\mathrm{C}_{\mathrm{i}-\mathrm{j}}\right)$. Basically, test series $\mathrm{C}$ is depicted in Fig. $2 \mathrm{~b}$ as well. The specimen dimensions were chosen relatively to the fastener diameter. In the specimen indication, subscript " $i$ " denotes the dowel diameter and " $\mathrm{j}$ " denotes the specimen number (replicates). Three replicates per test series were performed.

In series $\mathrm{A}$ and $\mathrm{B}$ the loaded edge distance was fixed to $h_{e}=4 d$, the unloaded edge $h-h_{e}=2 d$ and the thickness $t=2 d$. The specimen length in series A was $l=14 d$. The dowel dimensions used were 6,12 , and $24 \mathrm{~mm}$, respectively. The span of the specimens of series $B_{i}$ was fixed to $260 \mathrm{~mm}$ while both supports were $50 \mathrm{~mm}$ in length. The dowel diameter in this series was $12 \mathrm{~mm}$. For specimens in test series C timber beams of $45 \times 240 \mathrm{~mm}^{2}$ cross sectional area and a span of $1600 \mathrm{~mm}$ were used. The loaded edge distance was chosen relatively to the beam height as $\alpha=30,50$ and $70 \%$, respectively, with $\alpha=\frac{h_{e}}{h}$. The dowel diameter was $12 \mathrm{~mm}$ in

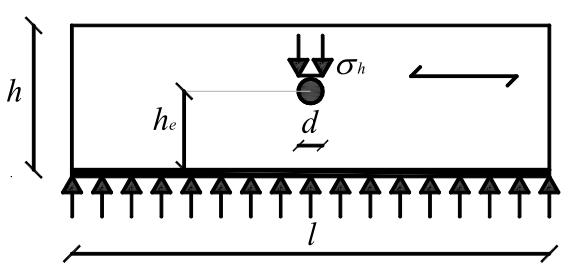

(a)

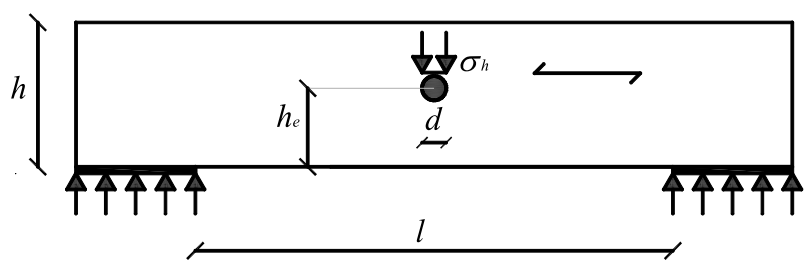

(b)

Fig. 2 (a) Full-constrained and (b) small scale bending specimens to determine embedment strength

Abb. 2 (a) Vollflächig aufgelagerte und (b) kleine Biegeprüfkörper zur Bestimmung der Lochleibungsfestigkeit 
Table 1 Overview of experimental program Tab. 1 Überblick über das Versuchsprogramm

\begin{tabular}{|c|c|c|c|c|c|c|}
\hline Specimen \# & $\begin{array}{l}d \\
{[\mathrm{~mm}]}\end{array}$ & $\begin{array}{l}t \\
{[\mathrm{~mm}]}\end{array}$ & $\begin{array}{l}h \\
{[\mathrm{~mm}]}\end{array}$ & $\begin{array}{l}l \\
{[\mathrm{~mm}]}\end{array}$ & $\begin{array}{l}h_{e} \\
{[\mathrm{~mm}]}\end{array}$ & Set-up \\
\hline $\mathrm{A}_{6 \mathrm{~mm}-\mathrm{j}}$ & 6 & 12 & 36 & 84 & 24 & Fig. 2a \\
\hline$A_{12 \mathrm{~mm}-\mathrm{j}}$ & 12 & 24 & 72 & 168 & 48 & Fig. 2a \\
\hline $\mathrm{A}_{24 \mathrm{~mm}-\mathrm{j}}$ & 24 & 48 & 144 & 336 & 96 & Fig. 2a \\
\hline$B_{12 \mathrm{~mm}-\mathrm{j}}$ & 12 & 24 & 72 & 260 & 48 & Fig. $2 b$ \\
\hline $\mathrm{C}_{12 \mathrm{~mm}-0.3-\mathrm{j}}$ & 12 & 45 & 240 & 1600 & 72 & Fig. $2 b$ \\
\hline $\mathrm{C}_{12 \mathrm{~mm}-0.5-\mathrm{j}}$ & 12 & 45 & 240 & 1600 & 120 & Fig. $2 b$ \\
\hline \multirow[t]{2}{*}{$\mathrm{C}_{12 \mathrm{~mm}-0.7 \mathrm{j}}$} & 12 & 45 & 240 & 1600 & 168 & Fig. $2 b$ \\
\hline & $j=1,2,3$ & & & & & \\
\hline
\end{tabular}

this test series as well in order to allow comparative analyses with test series B.

Table 1 gives an overview of the experimental program.

The dowel slenderness $\left(\lambda=\frac{t}{d}\right)$ in test series $\mathrm{C}$ is $\lambda=3 \frac{3}{4}$ which is larger than in test series $\mathrm{A}$ and $\mathrm{B}$, i.e., $\lambda=2$. According to the European Yield Model, plastic hinges in steel fasteners will develop only at slenderness ratios of approximately 8 till 10, although dependent upon the timber and steel quality. Hence, full-rigid behaviour of the dowel can be assumed in all experiments.

The timber species used was Norway spruce (Picea abies), with an average density $\rho_{12}=456 \mathrm{~kg} / \mathrm{m}^{3}$ and a moisture content $\omega=13.0 \%$. Prior to testing the specimens were stored in a climate room with a temperature of $20 \pm 2{ }^{\circ} \mathrm{C}$ and $65 \pm 5 \%$ relative humidity according to EN 383 (1993).

\section{Experimental set-up and ARAMIS}

The deformation field in the vicinity of the fastener was recorded by ARAMIS optical measuring system (GOM 2005). Measurements cover the entire load-slip response up to failure. ARAMIS is a non-contact full-field optical 3D deformation measuring system. The equipment combines digital speckle photogrammetry with 3D correlation techniques and thereby provides full-field 3D deformation measurements. From these, the system calculates and presents 2D strain fields. In addition, the load and rig displacement was recorded for all test series. It was assumed that the elastic response of the test rig is negligible compared to the elastic and plastic response of the test specimens, and therefore, the rig displacement was taken as the fastener slip.

The embedment tests of series A and B were performed by means of an Instron $5500 \mathrm{R}$ test rig at a constant rate of displacement of 0.5 or $0.8 \mathrm{~mm} / \mathrm{min}$. For each of the series at least two specimens were recorded by ARAMIS. Calibration of the measuring volume is carried out according to GOM ARAMIS User Manual (2005), i.e., with a cross $300 \times 300 \mathrm{~mm}^{2}$ with the distance between the cameras fixed

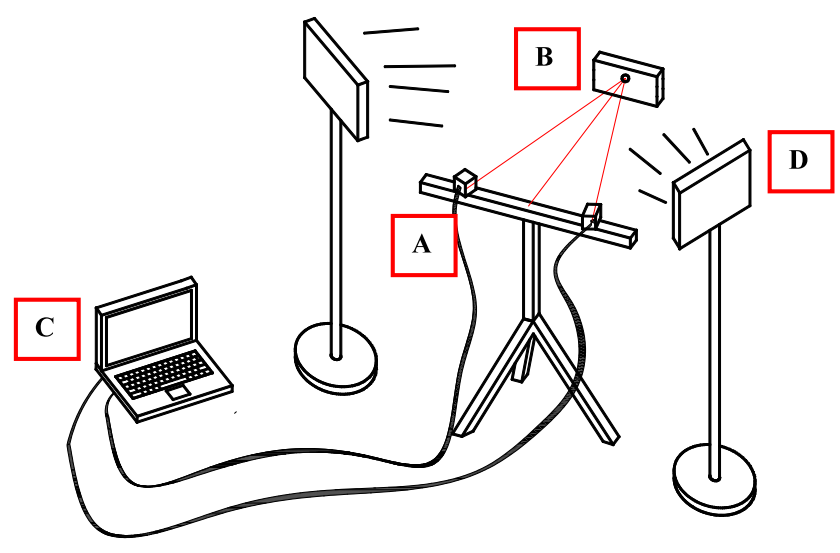

Fig. 3 Experimental set-up of a full-constrained specimen with ARAMIS. $A$ : ARAMIS digital cameras, $B$ : Test specimen, $C$ : Registration computer (data collection), $D$ : Cold-light source

Abb. 3 Versuchsaufbau eines vollflächig aufgelagerten Prüfkörpers mit dem optischen Messsystem ARAMIS. A: ARAMIS Digitalkamera, $B$ : Prüfkörper, $C$ : Computer zur Datenerfassung, $D$ : Kaltlichtquelle

at $470 \mathrm{~mm}$, while the measuring length was $1120 \mathrm{~mm}$. In order to obtain clear pictures the specimens were illuminated with two cold light sources. In Fig. 3 the test set-up is shown.

Images are captured during deformation of the specimen using two cameras. By arranging two cameras at an angle in front of the same specimen area, displacement captured at the same instants of time can be correlated.

\subsection{Load introduction device}

In order to allow a full view of the timber surface in the dowel vicinity a special load introduction device is needed since conventional steel side plates are not applicable. Figure 4 shows the test set-up and a detail of this device.

\section{Experimental results}

\subsection{Analyses of test series $\mathrm{A}_{\mathrm{i}}$}

Test series $\mathrm{A}_{\mathrm{i}}$ consists of the full-constrained test specimens. The embedment stress is defined according to the classical 
definition, i.e., as the load, $F$, divided by the dowel fastener diameter, $d$, and the timber width, $t$ :

$\sigma_{h}=\frac{F}{d t}$.

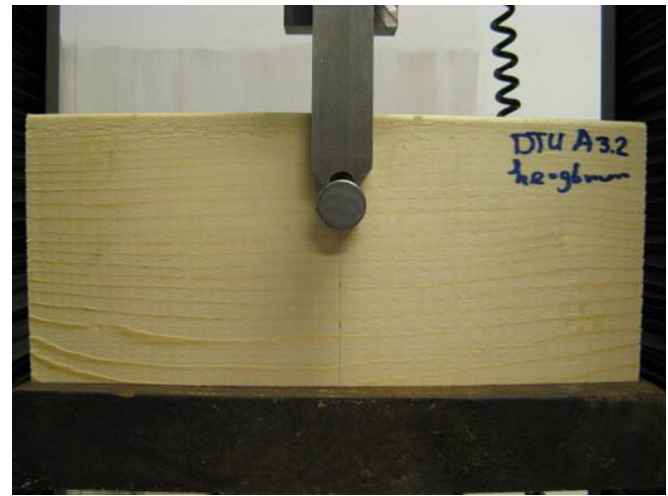

Fig. 4 Detail of the load introduction device

Abb. 4 Detail der Vorrichtung zur Lasteinleitung

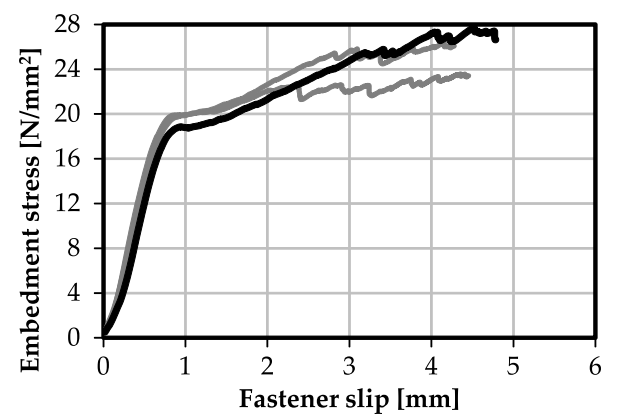

Fig. 5 Load-slip response of series $\mathrm{A}_{6 \mathrm{~mm}-\mathrm{j}}$ (full-constrained specimen, $6 \mathrm{~mm}$ dowel)

Abb. 5 Last-Verschiebungs-Kurve der $A_{6 m m-j}-$ Serien (vollflächig aufgelagerter Prüfkörper, 6 mm Dübel)
In Fig. 5, typical embedment stress-slip characteristics (or just load-slip response using (2)) are illustrated for dowels of $6 \mathrm{~mm}$ diameter (series $\mathrm{A}_{6 \mathrm{~mm}}$ ).

The initial linear elastic branch of the load-slip response is very limited in terms of slip. After reaching the yield load hardening was observed due to crushing of the timber fibers underneath the fasteners. This mechanism increases load sharing and material activation in regions outside the dowel vicinity. In addition, the fastener slip at ultimate failure is rather large compared to the yield slip and may be governed by fiber crushing and (micro) cracking.

Figure 6 shows the strain field perpendicular to the grain on the surface of an $\mathrm{A}_{6 \mathrm{~mm}}$-specimen, calculated from the full-field deformation measurements by the photogrammetric equipment. The dowel is located at the centre of the contour plot behind the white shaded area. This area is the result of large differences in stiffness between timber and steel, which cause convergence problems in the calculation algorithm used by ARAMIS. Therefore, the steel parts have to be masked in order to exclude them from numerical analyses. The strains presented here are the nominal strains given at a fixed scale ranging from $1 \%$ to $-1 \%$. Obviously, the large zone at the centre of the figure denotes compression. In addition, the numerical values at three different horizontal sections are illustrated in the right-hand side of Fig. 6 . Arrows indicate the intersection of the strain values with the $x$-axis, i.e., the strains change from compression to tension.

From the contour plot of Fig. 6 a strong load-sharing effect can be observed similarly to sill-type specimens as indicated by Van der Put (2006). The distance between both intersections of the lower section line and the $x$-axis is approximately $60 \mathrm{~mm}$. The loaded edge distance in these tests was $4 d=24 \mathrm{~mm}$. From this it follows that the stress distribution angle is $24 / 30$, i.e., $1: 1.25$. In this respect it is assumed that the reaction forces at the constrained edge are equally distributed. However, from the chart of Fig. 6 it can also be
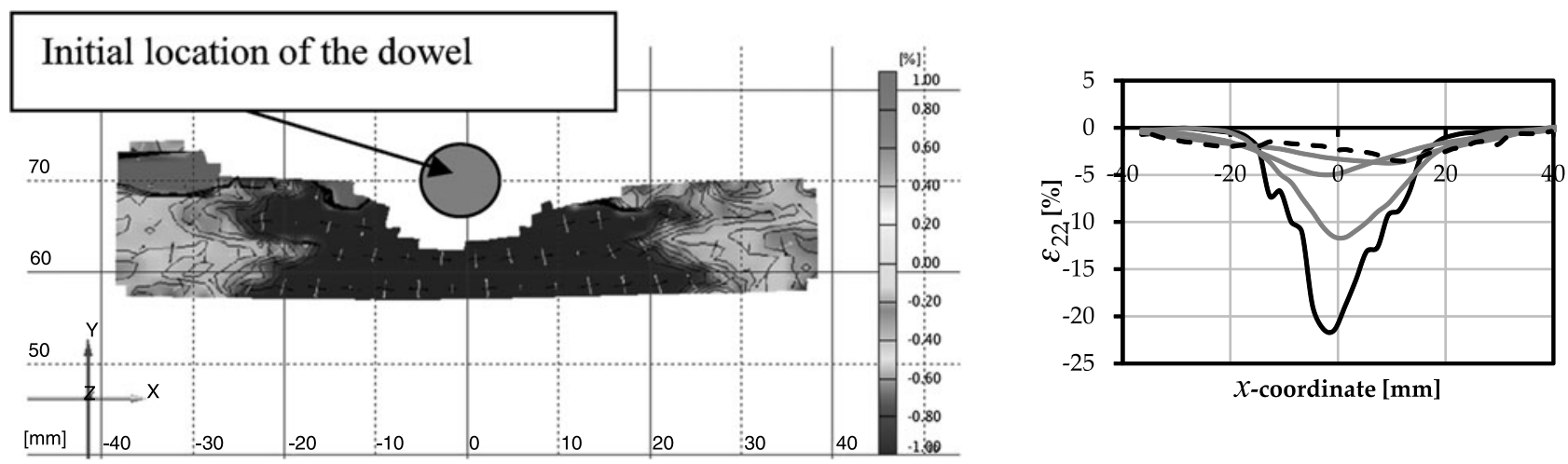

Fig. 6 Strain perpendicular to grain in the final stage of an $\mathrm{A}_{6 \mathrm{~mm}}$-specimen. Left: Contour plot, Right: Numerical values at several horizontal sections. Arrows mark the intersection points of strains in the lower section and the $x$-axis

Abb. 6 Dehnung quer zur Faser eines $\mathrm{A}_{6 \mathrm{~mm}}$-Prüfkörpers im Endstadium. Links: Konturplot, Rechts: Numerische Werte in verschiedenen Horizontschnitten; Pfeile markieren den Übergang von Druck- zu Zugspannung im unteren Schnitt 
Fig. 7 Strain perpendicular to grain in the final stage of an $\mathrm{A}_{12 \mathrm{~mm}}$-specimen

Abb. 7 Dehnung quer zur Faser eines $\mathrm{A}_{12 \mathrm{~mm}}$ Prüfkörpers im Endstadium



Fig. 8 Strain perpendicular to grain in the final stage of a $\mathrm{B}_{12 \mathrm{~mm}}$-specimen (smallbending with $12 \mathrm{~mm}$ dowel). Arrows mark the intersection points of strains in the lower section and the $x$-axis

Abb. 8 Dehnung quer zur Faser eines $\mathrm{B}_{12} \mathrm{~mm}$ Prüfkörpers im Endstadium (kleiner Biegeprüfkörper mit $12 \mathrm{~mm}$ Dübel). Pfeile markieren den Übergang von Druck- zu

Zugspannung im unteren Schnitt
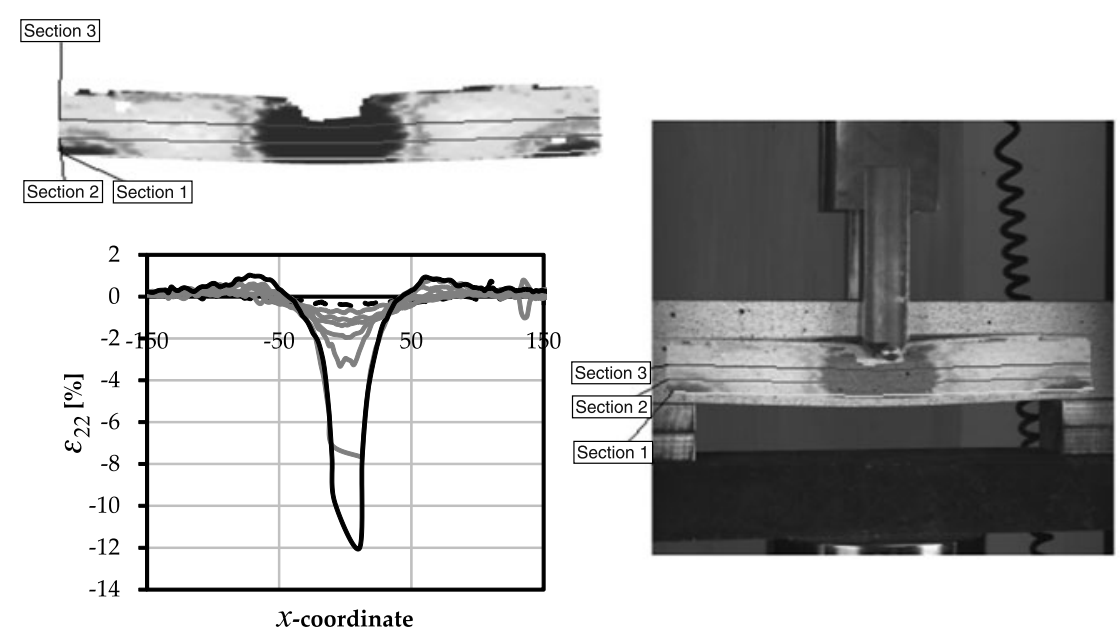

[\%]

1.00

0.80

0.60

0.40

0.20

0.00

$-0.20$

$-0.40$

$-0.60$

$-0.80$

$-1.00$ noticed that the compressive strains are actually rather local. Just beneath the dowel a strong stress concentration develops associated with high plastic strains $(\varepsilon>20 \%)$. Due to such high stress concentrations the $y$-axis of the contour plot needs to be fixed (in Fig. 6 from $-1 \%$ to $1 \%$ ). If not fixed, the image does not show isolines (lines which connect points with equal strain) because all isolines are located just beneath the dowel, i.e., the location with high strain gradients.

The strains perpendicular to the grain of an $\mathrm{A}_{12} \mathrm{~mm}^{-}$ specimen are shown in Fig. 7. The scale is fixed (compression only, with a maximum of $-3 \%$ ) in order to obtain a clear image for reasons given before. In this figure the scale of the $y$-axis is fixed to $3 \%$ compressive strain to indicate the stress concentration and the strain gradients in the embedment zone. If the scale was set equal to ( $1 \%$ and $-1 \%)$, similarly as for the specimen discussed, a similar contour plot is obtained, i.e., a large dark compressive zone which apparently indicates the load-sharing. The apparent load-sharing angle is indicated with white lines suggesting a triangle.
The load-slip response of these specimens is given further in Fig. 9.

\subsection{Analyses of test series $B_{12} \mathrm{~mm}$}

The specimens of series $B_{12} \mathrm{~mm}$ are the small-scale bending specimens as shown in Fig. 2. Because of the cross sectional dimensions and loaded edge distance the results can be compared with series $A_{12} \mathrm{mnm}$, which is a similar specimen with full-constrained boundary conditions over the specimen length.

In Fig. 8, the strains perpendicular to the grain are illustrated for several sections at the final stage of loading (nearly at failure). Again, the contour plot is fixed ranging from $1 \%$ to $-1 \%$ strain. The strain isolines appear to be rather circular. This was found in test series $\mathrm{C}_{\mathrm{i}-\mathrm{j}}$ as well (shown further on).

The chart of Fig. 8 gives the numerical values at three horizontal sections. The embedment strains only concentrate near the embedment zone and they vanish for distances of approximately $70 \mathrm{~mm}$ away from the dowel. This is observed by considering the intersection of the lower section 
line (section 1) and the $x$-axis which is marked by arrows. With a loaded edge distance of $48 \mathrm{~mm}$, this corresponds fairly well with a distribution of 1:1.5 $(=48 / 70)$, as obtained from tests on timber sills (Van der Put 2006). However, an equally distributed reaction at the loaded edge cannot be generated by a small-scale bending specimen as a result of the boundary conditions. In addition, embedment strains are again very local indicating that the suggestion of load-sharing through the specimen according to Van der Put (2006) is not confirmed.

Figure 9 illustrates the load-slip diagrams of both fullconstrained and small-scale bending test series for dowels of $12 \mathrm{~mm}$ diameter. It is noticed from this figure that fullconstrained specimens have a larger tangent modulus during hardening compared to small-bending specimens.

\subsection{Analyses of test series $C_{i}$}

As a consequence of the altered loaded edge distance for the specimens in this series the fastener is located in either the tensile-bending zone, the compressive-bending zone or on the neutral axis. This feature appears to be of great influence on the load-bearing capacity as well as hole elongation and material damage. Figure 10 subsequently shows pictures of

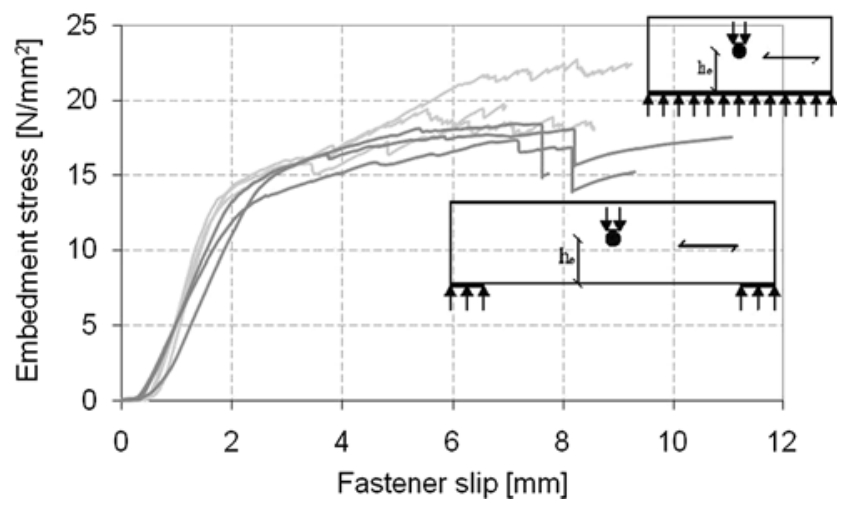

Fig. 9 Load-slip diagrams obtained from two set-ups with $12 \mathrm{~mm}$ diameter dowels

Abb. 9 Last-Verschiebungs-Diagramme zweier Versuchsanordnungen mit $12 \mathrm{~mm}$ Dübeln

Fig. 10 Fastener holes after failure of bending test specimens (series $\mathrm{C}_{\mathrm{i}-\mathrm{j}}$ ) Abb. 10 Dübellöcher nach dem Bruch der Biegeprüfkörper (Serien $\mathrm{C}_{\mathrm{i}-\mathrm{j}}$ ) the fastener holes for $\alpha \alpha=\frac{h_{e}}{h}=(0.3,0.5,0.7)$ after failure. It can thus be concluded that an increase in loaded edge distance results in an increase in plastic deformation of the timber underneath the fastener and thus large hole elongations.

Another feature which appears to be different among the test specimens $C_{i}$ is the shape of the strains indicated in Fig. 11 for one specimen per series. The scales are equally fixed (compression only). From these figures a compression zone can be noticed with a circular shape. With increasing loaded edge distance the size of the highly strained region in the embedment zone becomes larger. This suggests that a larger region becomes involved in load-transfer as a result of a larger edge distance. Compared to a small-scale bending specimen the shapes look very similar.

Load-slip curves of all experiments are given in Fig. 12. Larger load-edge distances result in higher stress levels at ultimate failure as well as in larger ultimate slip levels. This may explain why the size of the embedment strain concentration becomes larger for increasing loaded-edge distances. The bending stresses, which may interact with the embedment zone, possibly affect the load-bearing capacity as well. This phenomenon cannot be investigated with the limited data base available but should be treated in future research.

\subsection{Finite element modeling}

In order to verify the shape of the stress distributions obtained from ARAMIS some qualitative finite element simulations were conducted with the FEM program ABAQUS v6.7. In addition, the load transfer occurring in a highly orthotropic material like timber and in isotropic materials is compared, indicating that orthotropy results in material activation.

3D finite element models consisting of fully integrated linear elements were used. The interaction between steel dowel and timber was modeled by contact elements with Coulomb friction behaviour with coefficient $\mu=0.6$ and finite shear capacity. Both materials were modeled linear elastic. In reality, the timber underneath the dowel will yield

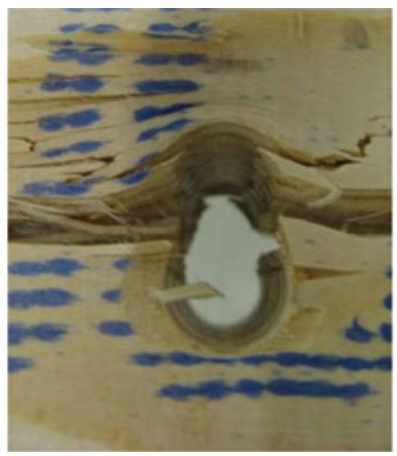

$\alpha=0.5$

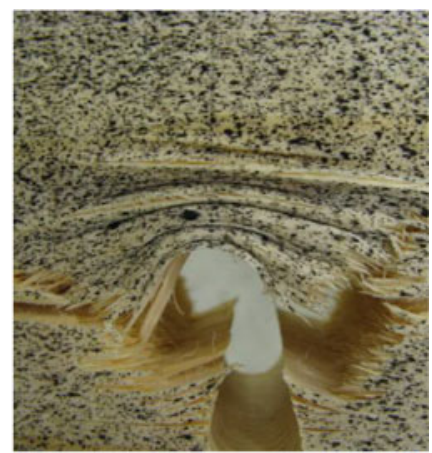

$\boldsymbol{\alpha}=\mathbf{0 . 7}$ 
Fig. 11 Strains perpendicular to the grain of bending specimens (series $\mathrm{C}_{\mathrm{i}-\mathrm{j}}$ ) Abb. 11 Dehnungen quer zur Faser der Biegeprüfkörper $\left(\right.$ Serien $\mathrm{C}_{\mathrm{i}-\mathrm{j}}$ )

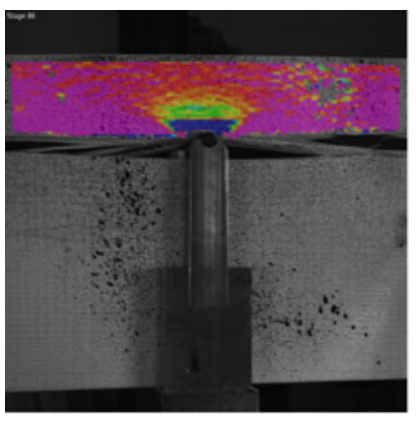

$\alpha=\mathbf{0 . 3}$

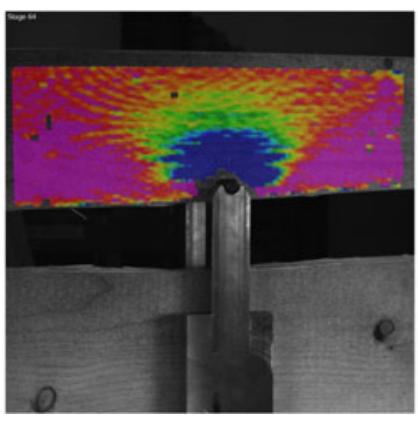

$\alpha=0.5$



$\boldsymbol{\alpha}=\mathbf{0 . 7}$
Fig. 12 Load-slip curves of all experiments on full-scale beams Abb. 12

Last-Verschiebungs-Kurven aller Versuche an Prüfkörpern in Gebrauchsabmessung

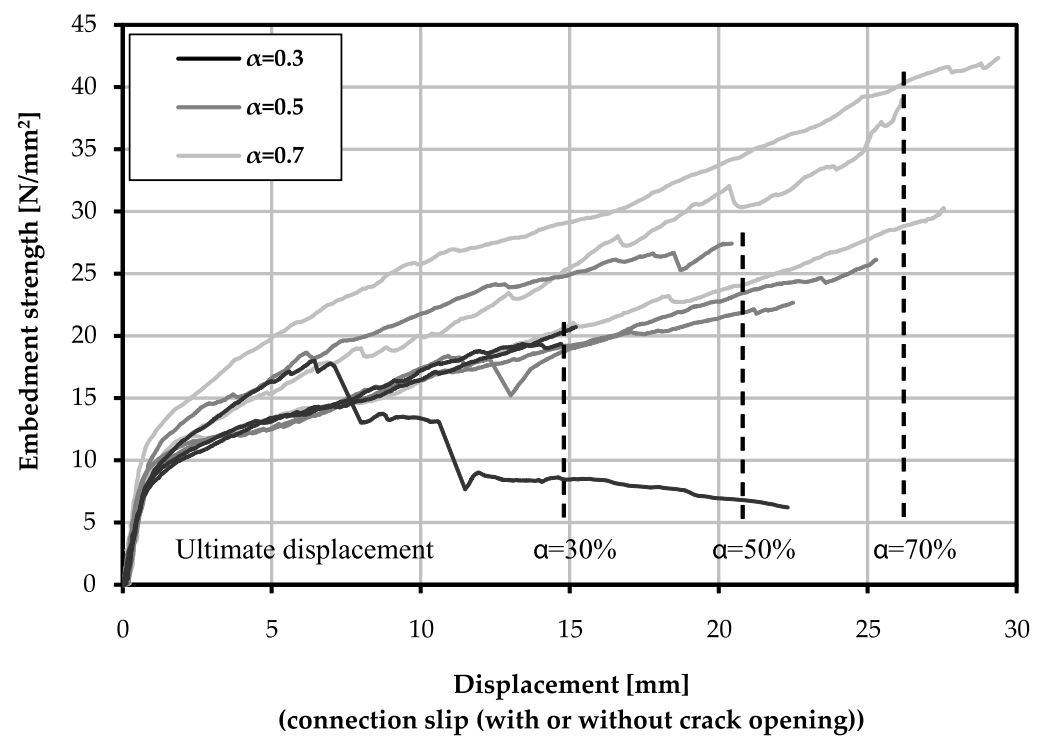

in an early stage of the experiment however, this is not accounted for as the intention was to visualize the overall stress distribution.

Figure 13 shows the perpendicular-to-grain stress distribution of an orthotropic material and two isotropic materials. The orthotropic material was defined with moduli of elasticity $E_{x}=12000 \mathrm{~N} / \mathrm{mm}^{2}$ and $E_{y}=E_{z}=E_{x} / 30$, and shear moduli $G_{x y}=G_{x z}=E_{x} / 16$ and $G_{y z}=G_{x y} / 10$. The contraction coefficient were set as $v_{x y}=v_{z y}=0.41$. Other values are obtained via generalized Hooke's law. The isotropic materials were defined by moduli of elasticity equal to $E_{x}$ and $E_{y}$, respectively. All analyses were displacement controlled. To account for the influence of elastic modulus all specimens were loaded up to a fixed embedment deformation. Large deflection theory is applied.

The specimens are fully constrained, i.e., supported over the whole lower edge. In Fig. 13, the contour plots are for a fixed range of 0 to $-50 \mathrm{MPa}$ to exclude stress concentrations and tensile stress. It appears that orthotropic materials transfer their load over a larger volume than the isotropic material. This is explained by the large elastic modulus in the direction perpendicular to the load compared to the elastic modulus in the loaded direction activating additional mater- ial. This can also be noticed from the stress gradients which are in the isotropic case larger indicated by the band width of the contours. In addition, the stress concentration underneath the fastener is very local indicating that a material point located somewhere in the middle of the specimen in line with the load applied becomes less loaded with increasing distance from the dowel. This confirms the local behaviour of embedment stresses in timber.

The stress shape looks very similar as measured by ARAMIS (series $A_{i-j}$ ), although the ARAMIS pictures show strains. The conversion from strain to stress is not straight forward as plasticity is included in the real measurements. Assuming a load step still in the linear elastic branch of the load-slip curve, the conversion is simply given by a generalized Hooke's law. Therefore pictures illustrating strain are similar to those indicating stress.

Figure 14 compares the stresses perpendicular to grain developing in case of small-scale bending tests (series $\left.\mathrm{B}_{12 \mathrm{~mm}}\right)$. Two different material models were used, i.e., orthotropic and isotropic with $E=400 \mathrm{~N} / \mathrm{mm}^{2}$.

The contour plots of Fig. 14 are fixed to 0 to $-10 \mathrm{MPa}$. Comparison of the stress shapes shows that perpendicular to the grain stresses are again more localized in case of 
Fig. 13 Stress perpendicular to the grain (FEM) for three different material models Abb. 13 Spannung quer zur Faser (FEM) für drei verschiedene Materialmodelle
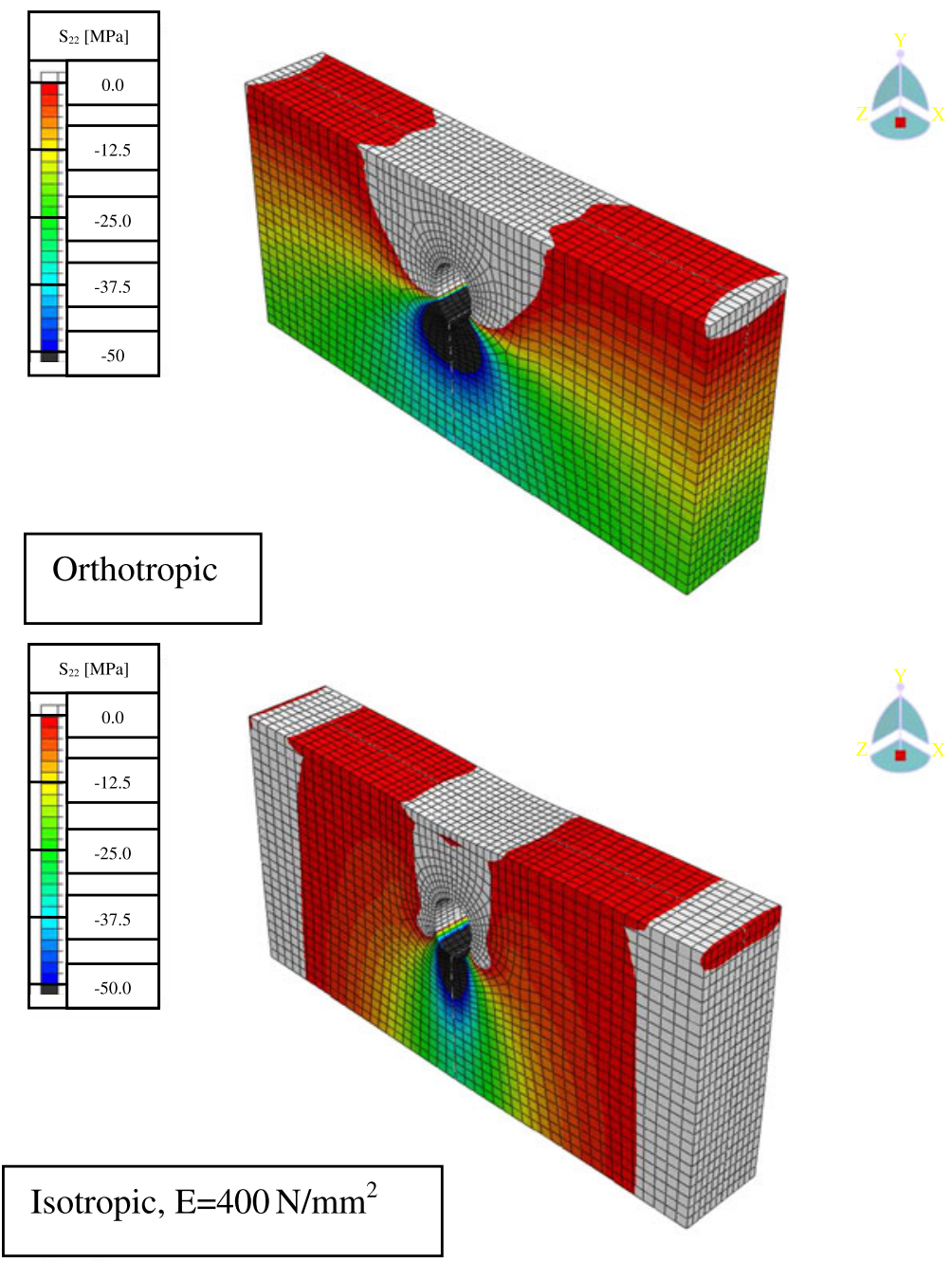

\section{Isotropic, $\mathrm{E}=400 \mathrm{~N} / \mathrm{mm}^{2}$}
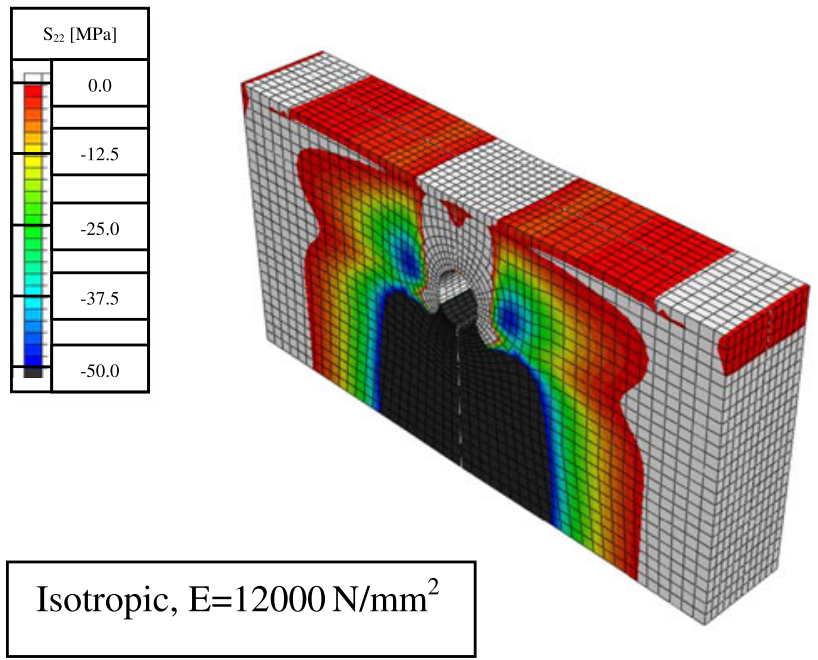

isotropic material, resulting in tensile zones along the beam span. The orthotropic case shows a larger region to be influenced by the dowel showing that timber may activate material outside the dowel vicinity as indicated earlier. Compar- ison of Fig. 13 and Fig. 14 shows the influence of tensilebending and compressive-bending stresses to be significant as the stress distribution changes significantly. This indicates that an influence of these stresses may be expected to affect 
Fig. 14 Stress perpendicular to the grain (FEM) in case of small-scale bending

Abb. 14 Spannung quer zur Faser (FEM) für kleine Biegeprüfkörper
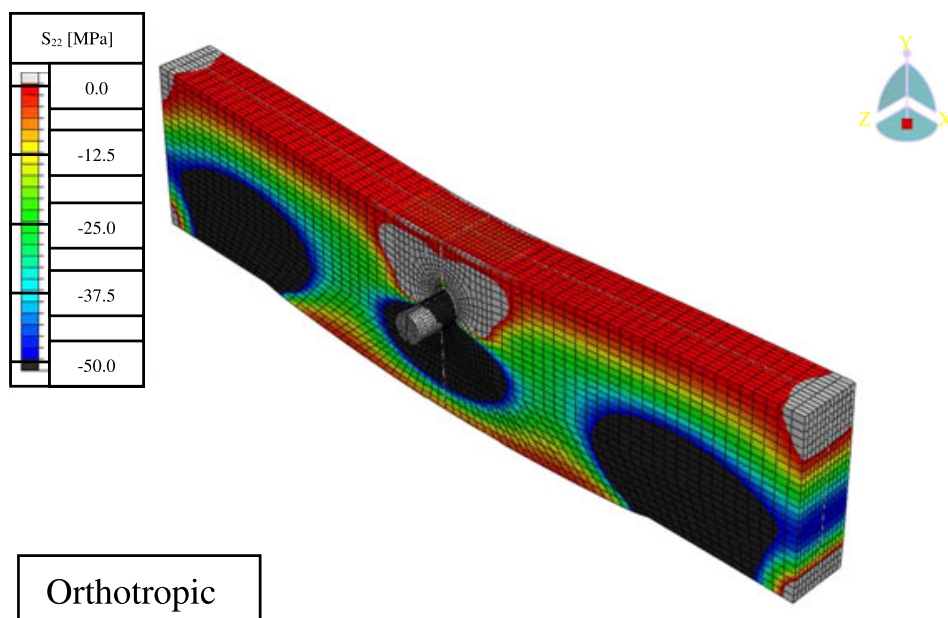

Orthotropic
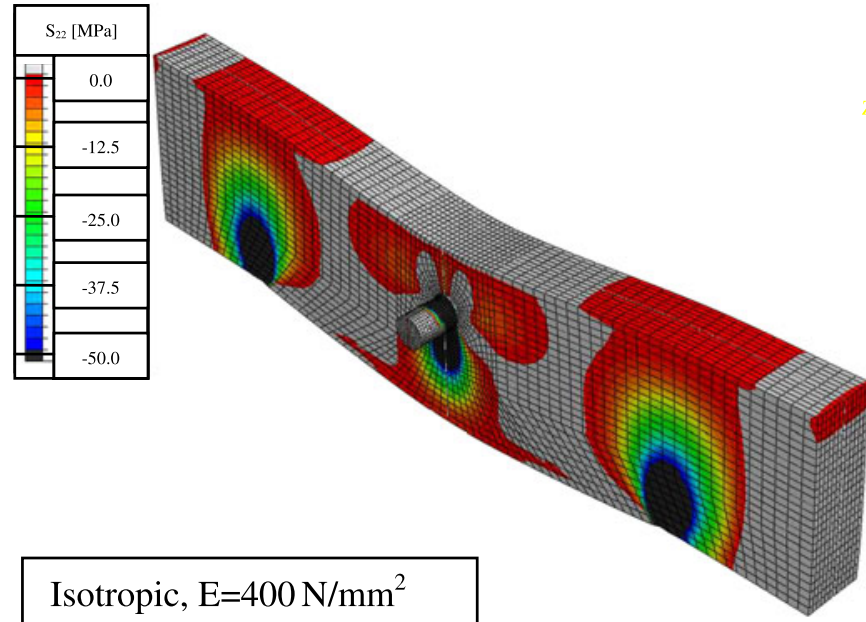

Isotropic, $\mathrm{E}=400 \mathrm{~N} / \mathrm{mm}^{2}$ the load-bearing capacity. Premature crack development can occur in case of too small loaded edge distances. Crack development is probably governed by the bending stresses. In this respect compressive-bending stresses reduce the effective stress at a crack tip while tensile-bending stresses result in an increase. This explains why the ultimate slip can increase with increasing loaded edge distance. Therefore, the ultimate load level and thus the load-bearing capacity increases.

\section{Conclusion and discussion}

The main objectives of the research were to determine the angle under which concentrated compressive stresses will be distributed through the timber specimen, as suggested by Van der Put (2006), and to investigate similarities in the embedment (bearing) behaviour underneath a fastener in an embedment test and a bending test on a full-scale beam loaded by one single dowel. Additional knowledge regarding an apparent load-sharing effect enables to verify a theo- retical model based on the equilibrium method of plasticity (Van der Put 2006). Besides, tests from literature with single fastener connections at mid span of a beam can be analyzed in more detail, from which it may follow that these specimens did not fail by primary splitting cracks but that embedment perpendicular to the grain was the main cause of failure. Such aspect may lead to a better and new point of view regarding timber connections perpendicular to the grain, and accordingly, a better understanding of their behaviour. This enables design rules to predict the load-bearing capacity more accurately.

For these purposes, 21 experiments have been conducted, i.e., 9 full-constrained embedding tests, 3 small-scale bending (embedment) tests and 9 full-scale bending tests. During these experiments the displacement fields are recorded by means of the non-contact full-field optical 3D deformation measuring system ARAMIS (GOM).

Generally, the strain distributions underneath the fasteners will show large concentration just underneath the fastener associated with large gradients. This causes images obtained either by ARAMIS or by FEM to be useless if 
load-transfer (or influence lines) is intended to be analyzed. A common technique to overcome this is to fix the scale at which the stresses are plotted. In this way a large portion of the entire stress range is captured just by two distinct colors (the maximum and minimum), and as so, intermediate colors of the spectrum are available to illustrate isolines to connect regions with equal stresses.

Consideration of contour plots at fixed scales suggests that compressive strains (and stresses under assumption of linear elastic behaviour and Hooke's law) are dispersed through the specimens at an angle of approximately 1:1.25 to 1:1.5 (as suggested by Van der Put 2006). However, fixing the scale also involves exclusion of strain gradients in the fastener vicinity. Considering absolute values of compressive strains at different horizontal sections shows embedment stress concentrations to be very local. The large gradients tend to vanish when the distance in both horizontal and vertical (loading) direction becomes larger. This applies to all specimens considered. Comparison of the results obtained by ARAMIS measurements and FEM calculation shows strong similarities indicating that the measurements are reliable. The FEM calculations presented in this article use linear elastic constitutive properties and contact elements to model the interaction between steel dowel and timber block. More sophisticated FEM models involving nonlinear constitutive relations as well as cracking are in hand, but will not be considered in this paper.

Comparison of test series on full-constrained and smallscale bending specimens loaded by equal fasteners indicates ultimate stress levels to be slightly higher for the former situation due to stringer hardening of the load-slip response. The ultimate slip levels at failure are comparable. Apparently, the influence of bending stresses cause the non-linear part of the response to be less stiff, although the differences are minor.

Analyses of test series $\mathrm{C}_{\mathrm{i}, \mathrm{j}}$ consisting of full-scale beams show that the loaded edge distance has strong influence on the load-bearing capacity, and also on the embedment deformation underneath the fastener. If the loaded edge distance is increased, the deformation increases significantly resulting in very strong local crushing and cracking in the fastener vicinity. Compared to the small-scale bending specimens these features are much more developed. This may be caused by the absolute values of loaded edge distances and an apparent reinforcing effect of bending-compressive stresses, and consequently, a strength decreasing effect of tensile-bending stresses.

Regarding the overall behaviour in terms of slip and associated stress levels it seems that no differences exist in case of small-scale bending and large scale bending specimens. The only aspect affected by the larger absolute edge distances is the ultimate slip level, and consequently, the ultimate stress level. This can be noticed from the load-slip diagrams given in the body text determined with dowels of $12 \mathrm{~mm}$ diameter (Fig. 9 and Fig. 12). All specimens started to yield at approximately $1 \mathrm{~mm}$ displacement and a stress level of $14-15 \mathrm{~N} / \mathrm{mm}^{2}$ after which a non-linear hardening branch developed up to failure. The ultimate failure load is governed by the ultimate displacements which increase with increasing loaded edge distance. The difference measured between the full-constrained and the small-scale bending specimens is negligible compared to the differences measured on full-scale beams. As the behaviour of both smallscale bending and full-scale bending are very comparable in terms of load-slip response and strain fields measured, it may be concluded that both test series failed by embedment perpendicular-to-grain.

Acknowledgements The authors wish to acknowledge COST Action E55 for the financial support to perform the so-called Short Term Scientific Mission from which this paper contains an important result. In addition, the financial support of the Dutch Technology Foundation STW, applied science division of NWO and the Technology Program of the Ministry of Economic Affairs, is gratefully acknowledged.

Open Access This article is distributed under the terms of the Creative Commons Attribution Noncommercial License which permits any noncommercial use, distribution, and reproduction in any medium, provided the original author(s) and source are credited.

\section{References}

Ballerini M (1999) A new set of experimental tests on beams loaded perpendicular-to-grain by dowel-type joints. In: Proceedings of CIB-W18/paper 32-7-2, Graz, Austria

EN 383 (1993) Timber structures. Test methods. Determination of embedding strength and foundation values of dowel type fasteners. Comité Européen de Normalisation (CEN) Brussels, Belgium

GOM Optical Measuring Techniques (2005) ARAMIS user manual, ARAMIS 4M v5.4.1. Gesellschaft für optische Messtechnik (GOM)

Kollmann F (1955) Technologie des Holzes und der Holzwerkstoffe, Bd 2. Springer, Berlin. ISBN: 0-387-11778-4

Sawata K, Yasumura M (2002) Determination of embedding strength of wood for dowel-type fasteners. J Wood Sci 48, The Japan Wood Research Society, Institute of Wood Technology, Akita, Japan

Schoenmakers JCM, Jorissen AJM, Leijten AJM (2009) Evaluation and modeling of perpendicular to grain embedment strength. Wood Sci Technol. doi: 10.1007/s00226-009-296-8

Van der Put TACM (1988) Explanation of the embedding strength of particle board. Stevin report HSC-6, Delft, the Netherlands, Faculty of Civil Engineering, Delft University of Technology

Van der Put TACM (2006) Derivation of the bearing strength perpendicular to the grain of locally loaded timber blocks. Publication of Delft Wood Science Foundation, available from www.DWSF.nl

Van der Put TACM, Leijten AJM (2000) Evaluation of perpendicular to grain failure of beams caused by concentrated loads of joints. In: Proceedings of CIB-W18/paper 33-7-7, Delft, The Netherlands

Whale LRJ, Smith I (1986) Mechanical joints in structural timberwork-information for probabilistic design. Timber Research and Development Association, Buckinghamshire 